\title{
Adelaide Russo, Le Peintre comme modèle. Du surréalisme à l'extrême contemporain
}

Fabio Scotto

\section{(2) OpenEdition}

1 Journals

\section{Edizione digitale}

URL: http://journals.openedition.org/studifrancesi/8058

DOI: ERREUR PDO dans /localdata/www-bin/Core/Core/Db/Db.class.php L.34 : SQLSTATE[HYO00]

[2006] MySQL server has gone away

ISSN: 2421-5856

\section{Editore}

Rosenberg \& Sellier

\section{Edizione cartacea}

Data di pubblicazione: 1 juillet 2009

Paginazione: 436

ISSN: 0039-2944

\section{Notizia bibliografica digitale}

Fabio Scotto, «Adelaide Russo, Le Peintre comme modèle. Du surréalisme à l'extrême contemporain», Studi Francesi [Online], 158 (LIII | II) | 2009, online dal 30 novembre 2015, consultato il 08 janvier 2021. URL: http://journals.openedition.org/studifrancesi/8058; DOI: https://doi.org/10.4000/studifrancesi. 8058

Questo documento è stato generato automaticamente il 8 janvier 2021.

\section{(c) (i) $\odot$}

Studi Francesi è distribuita con Licenza Creative Commons Attribuzione - Non commerciale - Non opere derivate 4.0 Internazionale. 


\title{
Adelaide Russo, Le Peintre comme modèle. Du surréalisme à l'extrême contemporain
}

\author{
Fabio Scotto
}

\section{NOTIZIA}

ADELAIDE RUSSO, Le Peintre comme modèle. Du surréalisme à l'extrême contemporain, Villeneuve d'Ascq, Presses Universitaires du Septentrion, 2007 («Perspectives»), pp.

302.

1 Di Adelaide Russo, docente alla Louisiana State University, si conoscono da tempo gli studi comparatistici rivolti alla poesia moderna, in particolare al rapporto con la teoria letteraria e le arti visive. Questo volume appare quindi come una sorta di summa del tragitto fin qui percorso in cui le ragioni della lirica e del pensiero che è ad essa sotteso si fondono agli impulsi più disparati dell'ekphrasis nello scandagliare ragioni genetiche e di poetica che attingono alla "visibilità" delle parole e alla "leggibilità" delle immagini. Il ricco itinerario storico che già il titolo tratteggia prende in esame alcune figure-chiave del periodo surrealista (da Aragon a Breton e Soupault) e post-surrealista (Ponge, Mandiargues, Leiris), fino a dar conto del lavoro di autori fondamentali del panorama attuale (Deguy, Noël) nel loro scrivere con la/della/nella pittura, nel segno della reciproca «hospitalité» (p. 265) fra le arti, in una sinergia che sappiamo quanto fertile nella cultura francese, specie dal Surrealismo in poi.

2 Strutturata in dodici capitoli, come attesta l'A., la monografia «analyse les commentaires de ceux qui sont à la fois amateurs et critiques d'art, et même parfois auteurs d'écrits esthétiques - voire philosophiques» (p. 12). Corredato di numerose riproduzioni anche a colori di dipinti (di Klee, Mirò, Picasso, fino a Dorny, Mousseau e altri), il viaggio prende spunto dal Surrealismo, avendo come riferimento critico l'approccio di Hubert Damisch - la Russo ricava infatti il titolo dal volume di Yves-Alain 
Bois Painting as Model (Mit Press, 1990) che è un omaggio a Damisch -, e sonda le potenzialità del pensiero pittorico, anche nell'accezione del "vedersi visti" di valéryana memoria. Nel cap. II (L'ekphrasis dans "Les Collages" de Louis Aragon: Ekplexis, Energeia, Escamotage, pp. 45-59) si dà conto dell'origine della passione d'Aragon per il collage dapprima scoperto grazie a Klee, poi fatto momento d'autocitazione. Vengono poi studiati nel cap. III (André Breton et les dispositifs du jugement: spéculaire, spéculatif, pp. 61-81) il triplice livello intrepretativo, narrativo e descrittivo della critica artistica di Breton, con particolare riferimento a Derain e Braque, mostrando tra l'altro in seguito, diciamo in sintesi, la retorica dell'immagine in Leiris (cap. V, pp. 107-122), l'analogia originaria tra Artaud critico d'arte e il primo Baudelaire (cap. VI, pp. 123-140), dove s'impone la centralità della figura di André Masson (vedasi anche il cap. XI), il nesso fra arte e musica in Ponge (cap. VIII, pp. 159-177), che si richiama a Giacometti. Particolarmente singolari nell'ultima parte gli studi dedicati a Fenosa letto poeticamente da Ponge, Vargaftig, Noël et Gleize (cap. IX, pp. 179-196), a Bona de Mandiargues nella ricezione del marito André Pieyre de Mandiargues (cap. X, pp. 197-219), fino al finale rivelatore della matrice filosofica della riflessione dell'A., tra Derrida, Lévinas e Deguy (cap. XII, pp. 265-278), a ribadire l'idea di ospitalità quale reciprocità fra pittore e poeta, due volti di una stessa figura, come questa scrittura saggistica, errante e disparata. Corredano il volume un'ampia Bibliographie (pp. 279-292) e un Index des noms propres (pp. 293-297). 